\title{
End-stage chronic thromboembolic pulmonary hypertension: is there still room for lung transplantation? - the past, the present and the future
}

\author{
Eleonora Faccioli, Andrea Dell'Amore \\ Thoracic Surgery Unit, Department of Cardiac, Thoracic and Vascular Sciences, University of Padova, Padova, Italy \\ Correspondence to: Andrea Dell'Amore. Thoracic Surgery Unit, Department of Cardiac, Thoracic and Vascular Sciences, University of Padova, Via \\ Giustiniani 2, 35128, Padova, Italy. Email: andrea.dellamore@unipd.it.
}

Submitted Aug 02, 2021. Accepted for publication Oct 13, 2021.

doi: 10.21037/acs-2021-pte-139

View this article at: https://dx.doi.org/10.21037/acs-2021-pte-139

\section{Introduction}

Pulmonary endarterectomy (PEA) has been established as the treatment of choice for Chronic thromboembolic pulmonary hypertension (CTEPH) if the thromboembolic lesions are surgically accessible, providing major hemodynamic and clinical improvements with a low early mortality in expert centers (1).

This procedure is performed through a median sternotomy with extracorporeal circulation and intermittent circulatory arrest in deep hypothermia. The pulmonary artery (PA) is opened, a suction dissector is introduced between the artery wall and the fibrosis, removing the fibrotic material from the wall and removing it with forceps $(1,2)$. Additionally, the CTEPH task force recommended that PEA centers should have extracorporeal membrane oxygenation (ECMO) available to manage potential intra and/or post-operative complications (3).

CTEPH is inoperable in at least $20-40 \%$ of patients because of distal disease or comorbidities (4).

Furthermore, while PEA is potentially curative, up to $51 \%$ of patients will experience persistent/recurrent CTEPH after surgery (5).

Balloon pulmonary angioplasty (BPA) is an alternative treatment that aims to disrupt organized clot material in the PA improving vascular blood flow. This procedure is less invasive than PEA as it only requires the cannulation of the femoral or jugular veins. Eligibility criteria for BPA are based on assessment of the anatomy of PA anatomy and function and lung perfusion (6). Regarding medical treatment in CTEPH, current guidelines approved
Riociguat, an oral guanylate cyclase stimulator, and Treprostinil, a subcutaneous prostacyclin analogue, for patients with inoperable CTEPH or persistent/recurrent pulmonary hypertension (PH) after PEA (1).

If all these treatments are not effective, lung transplantation can be considered as a salvage option only in highly selected patients and in highly specialized centers $(6,7)$.

\section{Discussion}

As reported by the last International Society for Heart and Lung Transplantation (ISHLT) consensus document for the selection of lung transplant candidates (8), the development of targeted medical therapy has led to a marked change in the timing for referral and listing of patients with idiopathic $\mathrm{PH}$ or secondary $\mathrm{PH}$ even if CTEPH is evident that preoperative pharmacological treatment is not beneficial in operable patients (2). This makes it all the more difficult to create universally accepted guidelines on lung transplantation in CTEPH patients and, for this reason, the experience reported in the current literature is very poor.

The 2019 ISHLT registries reported that only $1.5 \%$ of lung transplants performed worldwide are for nonidiopathic $\mathrm{PH}$, so we can assume that the percentage of transplants performed for CTEPH is even lower. At the same time, the authors who have reported their experience in the management of CTEPH have resorted to lung transplantation in very few cases.

In the majority of cases lung transplantation for CTEPH can be considered as a potential option after (I) the failure of or the exclusion from other procedures in patients 
with persistent $\mathrm{PH}$ and the possibility of a subsequent deterioration of right ventricular function; (II) inability to wean from ECMO after PEA (in this case transplantation should be considered in an emergency setting); (III) in case of stage IV CTEPH.

Data on the outcomes of lung transplantation in CTEPH can be extracted from only a few reported experiences and they are not satisfactory. Nierlick et al. (3) reported that 3 of the 4 transplanted patients died shortly after the intervention due to multi-organs failure while the last patient had a good long-term outcome after transplantation. More recently, the systematic application of intraoperative cardio-circulatory support and its prolongation in the postoperative period have improved the surgical results of lung transplantation for $\mathrm{PH}$ even in case of CTEPH. The chief explanation for this improvement is the prevention of acute primary graft dysfunction achieved with ECMO support $(3,7)$. In the case of CTEPH the lung-transplant should always be bilateral to avoid the entire flow of the right ventricle from being directed into a single vascular bed with subsequent high-risk of reperfusion edema. Heart and lung transplantation today is rarely performed for CTEPH because of a shortage of donors, but also because as has been demonstrated from PEA, the right heart can recover even in cases of severe preoperative dysfunction. The use of prolonged ECMO strategy in this case plays a significant role and gives the right ventricle time to recover function $(7,9)$.

In conclusion, lung transplant for CTEPH can be considered as a salvage option, only in highly selected cases as an alternative to failed PEA or as curative treatment in very peripheral thromboembolic disease not amenable to other medical or surgical treatment.

\section{Acknowledgments}

Funding: None.

\section{Footnote}

Conflicts of Interest: Both authors have no conflicts of interest to declare.

Open Access Statement: This is an Open Access article distributed in accordance with the Creative Commons Attribution-NonCommercial-NoDerivs 4.0 International License (CC BY-NC-ND 4.0), which permits the noncommercial replication and distribution of the article with the strict proviso that no changes or edits are made and the original work is properly cited (including links to both the formal publication through the relevant DOI and the license). See: https://creativecommons.org/licenses/by-nc-nd/4.0/.

\section{References}

1. Delcroix M, Torbicki A, Gopalan D, et al. ERS statement on chronic thromboembolic pulmonary hypertension. Eur Respir J 2021;57:2002828.

2. Kooperkamp H, Mehta I, Fary D, et al. Pulmonary Thromboendarterectomy for Pulmonary Hypertension Before Considering Transplant. Ochsner J 2017;17:66-70.

3. Nierlich P, Hold A, Ristl R. Outcome after surgical treatment of chronic thromboembolic pulmonary hypertension: dealing with different patient subsets. A single-centre experience. Eur J Cardiothorac Surg 2016;50:898-906.

4. Kim NH, Delcroix M, Jenkins DP, et al. Chronic thromboembolic pulmonary hypertension. J Am Coll Cardiol 2013;62:D92-9.

5. Humbert M. Pulmonary arterial hypertension and chronic thromboembolic pulmonary hypertension: pathophysiology. Eur Respir Rev 2010;19:59-63.

6. Ghofrani HA, D'Armini AM, Kim NH, et al. Interventional and pharmacological management of chronic thromboembolic pulmonary hypertension. Respir Med 2021. [Epub ahead of print].

7. Dell'Amore A, Campisi A, Congiu S, et al. Extracorporeal life support during and after bilateral sequential lung transplantation in patients with pulmonary artery hypertension. Artif Organs 2020;44:628-37.

8. Weill D, Benden C, Corris PA, et al. A consensus document for the selection of lung transplant candidates: 2014--an update from the Pulmonary Transplantation Council of the International Society for Heart and Lung Transplantation. J Heart Lung Transplant 2015;34:1-15.

9. Hoetzenecker K, Benazzo A, Stork T, et al. Bilateral lung transplantation on intraoperative extracorporeal membrane oxygenator: An observational study. J Thorac Cardiovasc Surg 2020;160:320-327.e1.

Cite this article as: Faccioli E, Dell'Amore A. End-stage chronic thromboembolic pulmonary hypertension: is there still room for lung transplantation?-the past, the present and the future. Ann Cardiothorac Surg 2022;11(2):161-162. doi: 10.21037/acs-2021-pte-139 